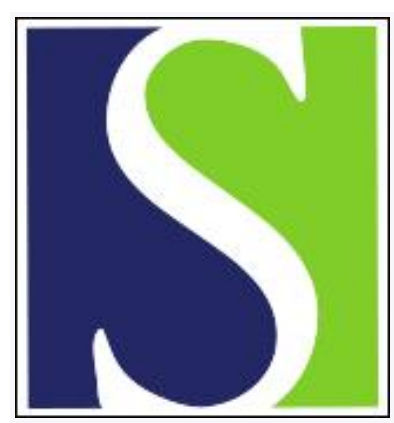

Scand J Work Environ Health 1991;17(1):38-45

https://doi.org/10.5271/sjweh.1736

Issue date: Feb 1991

Prevalence of epicondylitis and elbow pain in the meat-processing industry.

by Viikari-Juntura E, Kurppa K, Kuosma E, Huuskonen M, Kuorinka I, Ketola R, Konni U

Affiliation: Institute of Occupational Health, Helsinki, Finland.

This article in PubMed: www.ncbi.nlm.nih.gov/pubmed/2047805

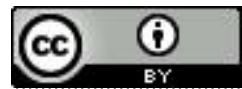




\title{
Prevalence of epicondylitis and elbow pain in the meat-processing industry
}

\author{
by Eira Viikari-Juntura, MD, Kari Kurppa, MD, Eeva Kuosma, MSc, Matti Huuskonen, MD, MSc, \\ Ilkka Kuorinka, MD, Ritva Ketola, Ulla Könni'
}

\begin{abstract}
VIIKARI-JUNTURA E, KURPPA K, KUOSMA E, HUUSKONEN M, KUORINKA I, KETOLA R, KÖNNI U. Prevalence of epicondylitis and elbow pain in the meat-processing industry. Scand $J$ Work Environ Health 1991;17:38-45. To determine the etiologic role of strenuous manual tasks in relation to epicondylitis, three clinical cross-sectional examinations were performed on meatcutters $(N=102)$, sausage makers $(\mathrm{N}=125)$, packers $(\mathrm{N}=150)$, and workers in nonstrenuous tasks $(\mathrm{N}=332)$. The workers in strenuous jobs reported elbow symptoms 1.6-1.8 times as often as those in nonstrenuous jobs. Female sausage makers also showed epicondylar tenderness more often than the women in nonstrenuous jobs. In all the cross-sectional examinations combined, seven cases $(0.8 \%)$ of epicondylitis were detected in both the strenuous and nonstrenuous jobs. A control for the possible sources of bias (leaving the company, changing task, being on sick leave) did not suggest a marked loss of potential cases of epicondylitis. A major role of strenuous tasks in the etiology of epicondylitis was not shown. However, because the number of clinical cases was small, the power of the study was low.
\end{abstract}

Key terms: cumulative trauma disorder, golfer's elbow, meatcutter, musculoskeletal disorder, overuse injury, packer, repetitive strain injury, sausage maker, tennis elbow, work-related disorders.

Epicondylitis is a common diagnosis in physicians' offices and occupational health care units. When afflicting a person with hand-intensive work, the ensuing disability may be remarkable. Although an important disease both from the human and economic point of view, little knowledge of its etiology is based on systematic research, and concepts of its pathomechanism are controversial $(1-4)$.

The etiologic role of various manual tasks in relation to epicondylitis can be studied in comparisons of the prevalence of the disease among occupational groups with different work loads imposed on the hand and wrist. A slightly increased prevalence of epicondylitis has been found among a group of meatcutters (5) and among blue-collar workers in the engineering industry $(6)$. However, in other studies $(7,8)$, workers in strenuous jobs have not shown a high prevalence of epicondylitis.

The design of etiologic studies concerning epicondylitis presents a problem. Comparison of the utilization of medical care, sickness absence rates, or the number of cases notified from different occupations to insurance companies may contain an in-built bias well-known to epidemiologists, the bias caused by "use-associated illness behavior" (9). Persons who work in hand-intensive jobs and are afflicted with epicondylitis probably seek medical care, have sick leave, and seek compensation more often than those with less strenuous job demands. This mechanism may

\footnotetext{
1 Institute of Occupational Health, Helsinki, Finland.
}

Reprint requests to: Dr E Viikari-Juntura, Department of Physiology, Institute of Occupational Health, Topeliuksenkatu 41 a A, SF-00250 Helsinki, Finland. lead to a serious distortion of true morbidity figures in longitudinal studies. On the other hand, crosssectional studies might underestimate the etiologic role of work due to the selection of afflicted persons out of hand-intensive work.

We decided to compare the occurrence of epicondylitis between manually strenuous and nonstrenuous jobs by making three clinical cross-sectional examinations within a period of 19 months in a population in which the selection mechanisms were controlled for. The study was carried out among meatcutters, sausage makers, packers, and workers in jobs not strenuous to the upper limb in a meat-processing plant with a high morbidity of epicondylitis in occupational disease statistics.

\section{Subjects and methods}

\section{General design}

This report is a part of a large investigation on the occurrences, cause-effect relations, and individual risk factors of selected upper-limb disorders. The study was carried out in Finland in a large meat-processing factory. The objectives of the investigation and the details of the study population have been described in another report (10). This article describes the prevalence of clinical epicondylitis, isolated clinical findings used in the diagnosis of epicondylitis, and elbow pain in three clinical cross-sectional examinations performed in October-November 1982, in October 1983, and in March-April 1984. The cross-sectional examinations consisted of a standardized questionnaire and a physiotherapist's clinical screening examination, on the basis 
of which the subjects were selected for a thorough clinical examination by a physiatrist. The follow-up of morbidity started on 1 October 1982, ended on 30 April 1985, and thereby covered 31 months (10).

\section{Subjects}

In the beginning of the study, all of the 308 permanent workers exposed to repetitive and manually strenuous tasks in the meat-processing plant were included in the study. A group of 289 workers in nonstrenuous tasks was selected so that it would be structurally similar with regard to sex, age, and duration of employment. The workers who entered the study groups between the cross-sectional examinations (69 into strenuous jobs and 43 into nonstrenuous jobs) were also included in the study. Altogether, the group with strenuous jobs consisted of 102 male meatcutters, 18 male and 107 female sausage makers, and 32 male and 118 female packers. The largest occupational groups with nonstrenuous jobs were supervisors, maintenance men, accountants, and office workers. The mean ages of the study groups varied between 35 and 39 years $(10)$.

Between October 1982 and April 1984, 28 permanent workers in strenuous jobs (3.5\% per year) and 36 workers in nonstrenuous jobs ( $4.8 \%$ per year) left the company. In addition, nine workers moved from strenuous to nonstrenuous jobs.

The rate of participation in the clinical screening examinations was $94.4 \%(94.1 \%$ for the workers in strenuous jobs and $94.7 \%$ for those in nonstrenuous jobs). The most common causes for not participating in the screening examinations were maternity leave, military service, and sick leave for reasons other than upper-limb disorders. Three workers were not examined because of a sick leave due to an upper-limb disorder. None of the three had epicondylitis.

During the cross-sectional examinations, six workers in strenuous jobs had been on sick leave because of epicondylitis. Three of them had been examined before the sick leave, and three were examined two to five weeks after the beginning of the sick leave.

\section{Job description and work analysis}

Meatcutters. Pork cutting was done in groups of six workers at a conveyor line. The workers rotated tasks daily. The work demanded high precision and was done at high speed, paced socially by the group. Each worker handled approximately $3000 \mathrm{~kg}$ of pork per day.

All stages of veal cutting were done by the same person, who cut approximately six carcasses (ie, $1200 \mathrm{~kg}$ of veal) per day. This work demanded high forces of both the cutting and the assisting hand. According to the classification of Silverstein et al (11), pork and veal cutting can be regarded as high-force and highrepetitive jobs.
Sausage makers. The making of sausages (ie, wieners, salamis, etc) consisted mainly of spraying the sausages, and hanging them on bars which were then lifted on a wheel rack. The workers rotated between these two tasks every 30-60 min. Depending on the type of sausage, the work cycle in spraying lasted 20 to $30 \mathrm{~s}$. Sausage spraying, in which the machine must be controlled during the work, demanded high precision. It also involved a risk of injury. The bar full of sausages weighed $3-7 \mathrm{~kg}$, and a wheel rack full of sausages weighed 140-180 kg. Sausage making can be regarded as a high-repetitive and low-force job (11) with some high-force tasks (eg, lifting the full bars and pushing the full wheel rack).

Packers. The packers rotated between various tasks (eg, pealing sausages, inserting them into a slicing machine, setting the slices into packages, setting the packages on a conveyor belt for price labeling, and collecting finished packages into bags. The job can be considered highly repetitive low-force work (11) with some high-force tasks (eg, pealing the sausages and lifting the bags and boxes full of sausages). Contrary to the sausage makers, the packers had some inspection tasks that allowed a recovery period for the upper limbs.

The room temperature was $16^{\circ} \mathrm{C}$ in the meatcutting departments, $20^{\circ} \mathrm{C}$ in the sausage-making departments, and 8 to $10^{\circ} \mathrm{C}$ in the packing departments.

The meatcutters and sausage makers worked on a group incentive basis, but the packers were paid by the hour. The meatcutters and sausage makers worked from 0700 to 1530 , and the packers had two-shift work.

\section{Clinical examination procedure}

All the workers were examined in the health care unit of the factory. The workers in strenuous and nonstrenuous tasks were examined in a mixed order. External cues were minimized by uniform clothing, all female workers being clothed as sausage makers and all male workers as meatcutters. The examinees were instructed not to volunteer their profession. The examination included a completion of a standardized questionnaire and a physiotherapist's screening examination on the same day. Workers with preselected screening findings or reported complaints in the elbow region were examined on the following day by a physiatrist (EV-J).

Questionnaires were filled out in the screening examinations performed on Mondays through Thursdays, and the physiatrist's examinations took place on Tuesdays through Fridays. The workweek was Monday through Friday, Saturday and Sunday being days off. The examinees were sent to the examinations by their foremen in an order that minimized any disturbance of production. Workers who could not come to the screening examination because of, for example, sick leave were examined after they returned to work. 
Questionnaire. The standardized questionnaire that was used to map the symptoms in the upper-limb and neck region and collect personal data and work history was largely based on the Nordic questionnaires for the analysis of musculoskeletal symptoms (12). The completeness of the responses to the questionnaire was checked by research assistants.

Clinical screening examination. A physiotherapist specially trained before the study, performed the clinical screening examination, which consisted of palpation of the epicondyles and a gripping test. The lateral/ medial epicondyles of both sides were palpated simultaneously, attention being paid to a stable palpation pressure. After the first cross-sectional examination, we felt that the palpation pressure had been too low. Therefore, the pressure was increased in the second cross-sectional examination.

To attain a better ștandardization of the palpation pressure, we measured the pressures by simulating palpations on a water-filled dynamometer tube containing a pressure transducer. At the time of the second cross-sectional examination, the palpation pressures of the physiotherapist and physiatrist ranged between 3 and $6 \mathrm{kPa}$. In the third cross-sectional examination, the device was used to practice palpations with a constant force $(4-5 \mathrm{kPa})$.

In the gripping test the subjects squeezed a tube-form hand dynamometer causing a pressure of $0.5 \mathrm{kp} / \mathrm{cm}^{2}$ with their elbow extended and their forearm in a neutral position. Pain in the elbow region while gripping was considered a positive finding.

In the first cross-sectional examination, the physiotherapist also recorded swelling at the epicondylar sites. Because no worker showed detectable swelling, this item was discarded from the other examinations. The screening examination also considered signs of tenosynovitis, peritendinitis, and selected nerve entrapment syndromes. (For the criteria, see reference 8.)

Physiatrist's examination. Workers with a clinical screening finding suggestive of epicondylitis (tenderness to palpation or pain while gripping) and/or those who reported symptoms in the elbow region during the preceding $7 \mathrm{~d}$ were examined on the following day by the physiatrist according to a predetermined scheme. The physiatrist's examination lasted $30 \mathrm{~min}$.

The criteria for a diagnosis of clinical epicondylitis included both tenderness to palpation at the lateral/ medial epicondyle and pain at the same epicondyle in resisted extension/flexion of the wrist and fingers with the elbow extended. After the examination, each worker was interviewed concerning the duration and onset of symptoms and whether any activity at work or during leisure time had triggered the symptoms.

The physiatrist also noted signs of tenosynovitis, peritendinitis, carpal tunnel syndrome, posterior in- terosseus nerve entrapment, cubital tunnel syndrome, tension neck, and cervical syndrome. (For the criteria, see reference 8.)

Clinical screening findings versus recorded morbidity. To study the extent to which the positive findings in the screening tests were signs of an incipient disease or residual signs of clinical-stage epicondylitis in the past, we reviewed the causes of the sick leaves in the medical files of the workers. Sick leaves due to epicondylitis were recorded three months after the second clinical cross-sectional examination and three months before the third. We chose these periods to avoid confounding by summer vacations. The frequency of sick leave due to epicondylitis was compared between those with and those without a positive finding. Because the occurrence of sick leave may depend on job demands, this analysis was restricted to the workers in strenuous jobs.

\section{Statistical analysis}

Rate ratio point estimates and $95 \%$ confidence intervals $(13,14)$ were calculated in the comparison of rates in the different groups. The effect of age and the number of years in the current occupation on the rate of elbow pain and clinical findings was investigated by linear trend analysis (15).

\section{Results}

\section{Reported elbow pain}

The prevalence of reported elbow pain did not differ in the three different cross-sectional examinations, with the exception of that of female packers, who reported more elbow pain in the second than in the first examination. Elbow pain reported in the third examination is presented in table 1. The workers in strenuous jobs reported symptoms in the elbow region during 12 months and during $7 \mathrm{~d}$ prior to the examination more often than those in nonstrenuous jobs. There were no significant differences between the different groups with strenuous jobs. The prevalence of elbow pain was similar among the meatcutters cutting veal and those cutting pork. The women reported more symptoms than the men both in the strenuous and in the nonstrenuous groups (strenuous and nonstrenuous jobs combined, $\mathrm{P}=0.13$, chi-square test).

In all the occupational groups, pain was slightly more common in the right than in the left elbow. For the 12 months prior to the third cross-sectional examination, the prevalence of pain in the right and left elbow was 24 and $16 \%$ for the meatcutters, 27 and $21 \%$ for the sausage makers, 28 and $17 \%$ for the female packers, 11 and $10 \%$ for the men in nonstrenuous jobs, and 16 and $12 \%$ for the women in nonstrenuous jobs, respectively. 
Among the female sausage makers, elbow pain reported for the preceding 12 months linearly increased with age (chi-square for the trend, $P<0.001$ ) and the number of years in the current occupation $(\mathrm{P}<0.01)$. Among the other occupational groups, such associations were not observed.

Table 2 presents the proportions of the workers who did not report recent elbow pain in any of the three cross-sectional examinations, of those who reported elbow pain in one or two examinations, and of those who reported pain in all three of the examinations. Most of the workers did not report recent elbow pain in any of the examinations. Recurring or persistent symptoms were reported by $4-12 \%$ of the workers in strenuous jobs and by $2-4 \%$ of the workers in nonstrenuous jobs.

\section{Clinical screening findings}

The prevalence of epicondylar tenderness among the workers in strenuous jobs was 3, 6, and $13 \%$ in the three clinical examinations, respectively, against 1,4 , and $8 \%$ among the workers in nonstrenuous jobs. The prevalence of positive findings in the gripping test did not differ markedly in the three clinical examinations $(5,5$, and $3 \%$ for the workers in strenuous jobs and 3,2 , and $2 \%$ for the workers in nonstrenuous jobs).

Table 3 shows the prevalence of positive findings in the physiotherapist's clinical screening tests in the third cross-sectional examination. The female sausage makers had the highest prevalence of epicondylar tenderness; this prevalence was statistically significantly higher than that of the women in nonstrenuous jobs. The prevalence of epicondylar tenderness among the female packers did not differ from that of the women in nonstrenuous jobs. Tenderness to palpation was more common among the women than the men in strenuous jobs $(\mathrm{P}<0.05$, chi-square test $)$. A similar finding $(P=0.06)$ was observed also for the workers in nonstrenuous jobs.

Among female sausage makers, epicondylar tenderness increased with the number of years in the current occupation (chi-square for the trend, $P=0.01$ ). In the other occupational groups, such associations were not observed.

Positive findings in the screening tests were related to elbow symptoms. Of those with epicondylar tenderness to palpation, 86, 63, and $66 \%$ reported recent elbow symptoms (symptoms occurring during the last $7 \mathrm{~d}$ ) in the three cross-sectional examinations, respectively. Of those with pain during gripping, 77,79 , and $88 \%$ reported recent elbow symptoms in the three cross-sectional examinations, respectively.

\section{Physiatrist's examination}

In all three of the cross-sectional examinations combined, the physiatrist detected 14 cases of clinical epicondylitis that fulfilled the predetermined criteria. Half of the cases involved six workers in strenuous jobs. The other half occurred among six workers in nonstrenuous jobs. The prevalence of clinical epicondylitis was $0.8 \%(0.6 \%$ for lateral and $0.2 \%$ for medial epicondylitis) among the workers in strenuous jobs and $0.8 \%(0.5 \%$ for lateral and $0.3 \%$ for medial epicondylitis) among those in nonstrenuous jobs.

The mean age of the workers with epicondylitis was 43 (range 24-54) years as against the mean of 38 (range 17-64) years for the nondiseased workers (table 4). The workers with epicondylitis had had their

Table 1. Pain in the elbow reported for the 12 months preceding and the 7 days preceding the third clinical cross-sectional examination.

\begin{tabular}{|c|c|c|c|}
\hline $\begin{array}{l}\text { Occupational } \\
\text { group }\end{array}$ & $\mathrm{N}$ & $\begin{array}{c}\text { During } \\
\text { the preceding } \\
12 \text { months } \\
(\%)\end{array}$ & $\begin{array}{l}\text { During } \\
\text { the preceding } \\
7 \text { days } \\
(\%)\end{array}$ \\
\hline \multicolumn{4}{|l|}{ Meatcutters } \\
\hline Men & 91 & $33.0^{\mathrm{a}}$ & 17.6 \\
\hline \multicolumn{4}{|c|}{ Sausage makers } \\
\hline $\begin{array}{l}\text { Men } \\
\text { Women }\end{array}$ & $\begin{array}{l}17 \\
94\end{array}$ & $\begin{array}{l}23.5 \\
38.3^{b}\end{array}$ & $\begin{array}{l}23.5 \\
25.3^{\prime}\end{array}$ \\
\hline \multicolumn{4}{|l|}{ Packers } \\
\hline $\begin{array}{l}\text { Men } \\
\text { Women }\end{array}$ & $\begin{array}{l}22 \\
97 \\
\end{array}$ & $\begin{array}{l}31.8 \\
36.1^{c}\end{array}$ & $\begin{array}{l}13.6 \\
21.9\end{array}$ \\
\hline \multicolumn{4}{|l|}{ Total } \\
\hline \multicolumn{4}{|c|}{ Strenuous jobs } \\
\hline $\begin{array}{l}\text { Men } \\
\text { Women }\end{array}$ & $\begin{array}{l}130 \\
191\end{array}$ & $\begin{array}{l}31.5^{d} \\
37.2^{e}\end{array}$ & $\begin{array}{l}17.7 \\
23.68\end{array}$ \\
\hline Total & 321 & 34.9 & 21.2 \\
\hline $\begin{array}{l}\text { Nonstrenuo } \\
\text { Men } \\
\text { Women }\end{array}$ & $\begin{array}{l}124 \\
164\end{array}$ & $\begin{array}{l}17.7 \\
22.6\end{array}$ & $\begin{array}{l}10.5 \\
13.4\end{array}$ \\
\hline Total & 288 & 20.5 & 12.2 \\
\hline
\end{tabular}

Crude risk ratio (with the $95 \%$ confidence interval in parentheses) in com parison with the nonstrenuous job and the same sex: a $1.9(1.2-3.0)$,
b $1.7(1.2-2.5)$, c $1.6(1.1-2.4)$, d $1.8(1.1-2.8)$, e $1.6(1.2-2.3),+1.9$ $(1.1-3.2), 91.8(1.1-2.8)$.

Table 2. Pain in the elbow (\%) reported for the preceding 7 days - the three cross-sectional studies combined. ${ }^{a}$

\begin{tabular}{|c|c|c|c|c|c|c|}
\hline \multirow{2}{*}{$\begin{array}{l}\text { Number of } \\
\text { examinations } \\
\text { with reported } \\
\text { pain }\end{array}$} & \multirow{2}{*}{$\begin{array}{c}\text { Male } \\
\text { meat- } \\
\text { cutters } \\
(\mathrm{N}=89)\end{array}$} & \multirow{2}{*}{$\begin{array}{l}\text { Female } \\
\text { sausage } \\
\text { makers } \\
(N=67)\end{array}$} & \multirow{2}{*}{$\begin{array}{l}\text { Female } \\
\text { packers } \\
(N=76)\end{array}$} & \multicolumn{2}{|c|}{ Nonstrenuous jobs } & \multirow{2}{*}{$\begin{array}{c}\text { Total } \\
(\mathbf{N}=475)\end{array}$} \\
\hline & & & & $\begin{array}{c}\text { Men } \\
(N=105)\end{array}$ & $\begin{array}{c}\text { Women } \\
(N=138)\end{array}$ & \\
\hline None & 71 & 51 & 63 & 82 & 76 & 71 \\
\hline One to two & 25 & 37 & 33 & 16 & 20 & 24 \\
\hline Three & 4 & 12 & 4 & 2 & 4 & 5 \\
\hline
\end{tabular}

a Workers who participated in all three examinations included. 
present work task for an average of 11 (range 3-23) years as against 9 (range $0.2-35$ ) years for the unafflicted workers. In eight individuals $(67 \%)$ of the

Table 3. Findings of the clinical screening in the third crosssectional examination.

\begin{tabular}{lccc}
\hline $\begin{array}{l}\text { Occupational } \\
\text { group }\end{array}$ & $\mathrm{N}$ & $\begin{array}{c}\text { Epicondylar } \\
\text { tenderness } \\
\text { on palpation } \\
(\%)\end{array}$ & $\begin{array}{c}\text { Pain in } \\
\text { gripping } \\
(\%)\end{array}$ \\
\hline $\begin{array}{l}\text { Meatcutters } \\
\quad \text { Men }\end{array}$ & 91 & 11.0 & 2.2 \\
$\begin{array}{l}\text { Sausage makers } \\
\quad \text { Men }\end{array}$ & 17 & 5.9 & 0.0 \\
$\quad$ Women & 95 & $23.2^{\mathrm{b}}$ & 5.3 \\
Packers & & & \\
$\quad$ Men & 22 & 0.0 & 0.0 \\
$\quad$ Women & 97 & 9.3 & 2.1 \\
\hline Total & & & \\
$\quad$ Strenuous jobs & & & \\
$\quad$ Men & 130 & 8.5 & 1.5 \\
$\quad$ Women & 192 & $16.1^{\circ}$ & 3.6 \\
$\quad$ Total & 322 & 13.0 & 2.8 \\
$\quad$ Nonstrenuous jobs & & & \\
$\quad$ Men & 124 & 4.8 & 0.8 \\
$\quad$ Women & 164 & 11.0 & 3.7 \\
$\quad$ Total & 288 & 8.3 & 2.4 \\
\hline
\end{tabular}

a Number of subjects with tenderness in at least one epicondyle (right/left, lateral/medial).

b Crude risk ratio 2.1 (95\% confidence interval 1.2-3.7) in comparison with the women in nonstrenuous jobs.

c Crude risk ratio 1.9 (95\% confidence interval 1.0-3.6) in comparison with the men in strenuous jobs.
12 with epicondylitis the symptoms had appeared insidiously without exceptional strenuous tasks or direct trauma known to the individual.

All six of the workers with epicondylitis in strenuous jobs had reported symptoms in the elbow region within the week preceding the screening examination. Two of the six workers with epicondylitis in nonstrenuous jobs had not reported elbow pain during the preceding week.

No individual with epicondylitis reported rheumatoid arthritis, gout, or other chronic diseases.

One of the workers (a meatcutter) had clinical epicondylitis in both the first and the third crosssectional examination at the same epicondyle; at the second examination he had symptoms and tenderness to palpation but not clinical epicondylitis, according to our criteria. Another subject (a payroll clerk) had similarly localized epicondylitis with an unknown etiology in the first and the second cross-sectional examinations.

All of the six workers in strenuous jobs except one meatcutter had been or went on sick leave (after visiting one of the company doctors or a consulting specialist) close to the time (three months before or after) when their epicondylitis was diagnosed by the physiatrist. The main diagnosis for the sick leave was epicondylitis for three of them, and tenosynovitis or peritendinitis for two of them. One of the six workers

Table 4. Individuals with clinical epicondylitis in one of the three cross-sectional examinations.

\begin{tabular}{|c|c|c|c|c|c|}
\hline \multirow{3}{*}{$\begin{array}{c}\text { Age } \\
\text { (years) }\end{array}$} & \multirow{3}{*}{ Sex } & \multirow{3}{*}{$\begin{array}{l}\text { Years in } \\
\text { current } \\
\text { occupation }\end{array}$} & \multicolumn{2}{|c|}{ Location of epicondylitis ${ }^{a}$} & \multirow{3}{*}{ Onset of symptoms } \\
\hline & & & Right & Left & \\
\hline & & & Lateral Medial & Lateral Medial & \\
\hline
\end{tabular}

Workers in

strenuous jobs

Sausage maker

Sausage maker

Sausage maker

Sausage maker

Meatcutter

$\begin{array}{ll}43 & \text { Female } \\ 41 & \text { Female } \\ 49 & \text { Female } \\ 24 & \text { Male } \\ 39 & \text { N.ale }\end{array}$

Meatcutter

Workers in

nonstrenuous jobs

Payroll clerk

Shop manager

Maintenance man $^{\mathrm{b}}$ Maintenance man Foreman

Telesales person

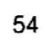

Male

40

48

Female Female

17.0
3.0
11.4
6.0
13.7

18.9

7.0 14.0

-
+
+
+
-

$\begin{array}{ccc}+ & - & - \\ + & - & - \\ - & \overrightarrow{1+} & - \\ - & + & (+)\end{array}$

Insidious

Insidious

Insidious

Insidious

Symptoms appeared after exceptionally strenuous task of skinning pig legs five years ago Insidious

Insidious

Symptoms appeared after cutting cheese for several hours (exceptional task) Insidious Insidious

Symptoms appeared after removing a heavy box

Symptoms appeared after strenuous cross-country skiing

\footnotetext{
a $+=$ clinical epicondylitis (criteria given in the text), $(+)=$ epicondylar tenderness on palpation, $-=$ no finding related to epicondylitis.
}

b Left hand dominant. 
in nonstrenuous jobs (a payroll clerk) had sought medical aid; she was operated on four months after the second examination. None of the 12 individuals with epicondylitis had changed jobs because of their disease.

\section{Clinical screening findings versus recorded morbidity}

Of the 19 workers with epicondylar tenderness to palpation in strenuous jobs in the second cross-sectional examination, two (11\%) went on sick leave because of epicondylitis with a similar location during the following three months as against seven of $283(2 \%)$ of those without this finding ( $\mathrm{P}=0.10$, Fisher's exact fourfold table test). The subjects with epicondylar tenderness in the third cross-sectional examination had also been on sick leave because of epicondylitis during the preceding three months more often ( 2 of 42 , $5 \%$ ) than those without epicondylar tenderness ( 3 of $280,1 \%)(\mathrm{P}=0.13)$. Of the 14 workers with a positive result in the gripping test in the second crosssectional examination, two $(14 \%)$ went on sick leave because of epicondylitis in the same elbow as against 7 of $288(2 \%)$ of those without this finding $(P=0.06)$. None of the nine workers with a positive result in the gripping test had been on sick leave because of epicondylitis as against 5 of $313(2 \%)$ of those with a negative test result.

\section{Discussion}

The results showed that reported elbow pain was more common among the workers in strenuous jobs than among those in nonstrenuous jobs. The female sausage makers also showed epicondylar tenderness more often than the women in nonstrenuous jobs. However, clinical epicondylitis was as common in strenuous as in nonstrenuous jobs.

In another clinical cross-sectional study, a group of 90 male meatcutters showed an increased prevalence of epicondylitis $(9 \%)$ in a comparison with 77 construction foremen $(1 \%)$ although the difference seemed to be due partly to an overrepresentation of older workers among the meatcutters (5). In a study among 540 predominantly male subjects in a modern engineering plant, the prevalence of lateral epicondylitis was not related to job category when the comparison was made with elbow stress in the job (6). In the same study, blue-collar workers showed a slightly higher prevalence of epicondylitis than white-collar workers (estimated prevalence 11.0 and $5.3 \%$, respectively; the difference was not statistically significant). The difference may at least partly have been due to the fact that only subjects with reported symptoms were clinically examined.

In a study comparing 152 assembly-line packers with 133 shop assistants, no statistically significant difference in the prevalence of epicondylitis (3 and $2 \%$, respectively) was found (7). On the other hand, a considerably high prevalence of $1-3 \%$ was found for lateral epicondylitis in a study among a general population between the ages of 31 and 74 years (16).

Although the prevalence of clinical epicondylitis did not differ between strenuous and nonstrenuous jobs, sick leaves were much more common in strenuous than in nonstrenuous jobs. The most probable reason is that a meatcutter, sausage maker, or packer with epicondylitis is more disabled in his or her work than, for example, a foreman. (See reference 10.)

The screening procedure very probably detected all prevalent cases of epicondylitis, because all workers with reported elbow pain or at least one positive finding in the screening tests were examined by the physiatrist. The $0.6 \%$ prevalence of lateral and $0.2 \%$ prevalence of medial epicondylitis among the workers in strenuous jobs and the $0.5 \%$ prevalence of lateral and $0.3 \%$ of medial epicondylitis among the workers in nonstrenuous jobs in our study were close to those reported for workers in some previous studies (7, 8, 17, Kuorinka: personal communication) but lower than those of some other studies $(5,6)$. Although most studies described similar diagnostic criteria, the results cannot be directly compared because differences in the technique of examination (eg, site and pressure of palpation) might explain the variations. The results of other studies and this study show, however, that the prevalence is not necessarily prominent in populations doing strenuous manual tasks.

Our results concerning clinical epicondylitis could be biased if those afflicted had left the company or changed tasks between the cross-sectional examinations. However, no worker left because of epicondylitis. One packer, for whom a diagnosis of epicondylitis had not been made, changed tasks because of wrist and elbow pain. In addition, one packer and one sausage maker had had a history of epicondylitis, although they did not mention this history as the reason for changing tasks (10).

Another source of bias could be that workers with clinical epicondylitis were on sick leave during the cross-sectional examinations and were not examined. Of the three workers that were not examined because of sick leave, none had a diagnosis of epicondylitis. Six workers in strenuous jobs were on sick leave because of epicondylitis (diagnosed by the company doctors or consulting specialists) during the cross-sectional examinations. All of them were clinically examined, and a diagnosis of epicondylitis was made for one of them. Of the remaining five workers, two had been examined before the sick leave and three after the sick leave. This latter group of three workers is a possible source of bias for which the time of the clinical examination could have been postponed because of sick leave due to epicondylitis. Therefore, the maximal number of workers in strenuous jobs with epicondylitis could have been nine (prevalence $1.1 \%$ ) instead of six. 
A bias could have resulted also if the selection of workers occurred very early (ie, during the preemployment examination or the probationary period before employment). Our results did not suggest that selection had occurred during the probationary period (10).

The female sausage makers more often showed epicondylar tenderness than the women in nonstrenuous jobs, and the meatcutters showed a tendency towards more epicondylar tenderness than the men in nonstrenuous jobs. Epicondylar tenderness to palpation without distinct pain at the epicondyle in resisted extension/flexion of the wrist and fingers is not a sufficient criterion for epicondylitis. However, in our univariate analysis, epicondylar tenderness showed a weak predictive value for the future occurrence of epicondylitis.

The fact that the women had a higher prevalence of tenderness to palpation than the men may have been due to a difference in the threshold of tenderness to pressure between women and men (18).

The number of workers with positive epicondylar tenderness increased from the first to the third crosssectional examination. The ratio of epicondylar tenderness between the workers in strenuous and nonstrenuous jobs did not, however, change from one crosssectional examination to another. The increased prevalence of epicondylar tenderness was conceivably due to an increase in palpation pressure.

Despite an increase in the number of subjects with epicondylar tenderness, there was no increase in the number of subjects with a clinical stage of epicondylitis in the different cross-sectional examinations (seven, two, and five subjects in the first to the third cross-sectional examinations, respectively). Therefore, the increase in the palpation pressure did not make the screening procedure more efficient. On the contrary, in the second and third cross-sectional examinations a greater proportion of subjects with epicondylar tenderness than in the first cross-sectional examination had no current elbow symptoms.

The prevalence of those with a positive gripping test was stable from one cross-sectional study to another. This sign was also related to current elbow pain and showed a weak predictive value for future afflictions of epicondylitis.

The subjects with a clinical stage of epicondylitis were typically older than 40 years, the disorder was located in the dominant hand, and they reported that the symptoms had started insidiously without an exceptional task or trauma. A low occurrence at ages below 40 years has been reported in other studies also $(1,4,5)$. The proportion of cases with an insidious onset was rather high $(44 \%)$ also among the patients operated on because of epicondylitis in the study of Goldie (1).

Reported elbow pain and epicondylar tenderness were related to age and years in the current occupation among female sausage makers. Because age and years in the current occupation were correlated (corre- lation coefficient 0.52 for female sausage makers), we do not know whether these results were due to repeated occupational traumas to the elbow or to a general aging process.

A major role of strenuous manual tasks in the etiology of epicondylitis was not shown in our study. Because the number of clinical cases of epicondylitis was not high, the power of our study was low. Yet, we believe that our screening procedure detected the potential cases of epicondylitis so that, apart from the three workers who were examined after their sick leaves, we did not miss many cases of the disease.

Previous studies and this study have given little evidence of the etiologic role of strenuous manual tasks in the occurrence of epicondylitis. Therefore, we do not know whether efforts to prevent the disease by minimizing force and frequency demands in handintensive work will decrease the incidence of epicondylitis. Such measures can, however, be recommended, because they probably have a favorable effect on the disability caused by the disease.

\section{Acknowledgments}

We are indebted to Ms T Merisalo for her willingness and care in performing the physical examinations and to the Finnish Work Environment Fund for its financial support.

\section{References}

1. Goldie I. Epicondylitis lateralis humeri (epicondylitis or tennis elbow): a pathogenetical study. Acta Chir Scand Suppl 1964;339:1-119.

2. Coonrad RW, Hooper R. Tennis elbow: its course, natural history, conservative and surgical management. $\mathbf{J}$ Bone Jt Surg 1973;55A:1177-82.

3. Kurppa K, Waris P, Rokkanen P. Tennis elbow: lateral elbow pain syndrome. Scand J Work Environ Health 1979;5(suppl 3):15-8.

4. Viikari-Juntura E. Tenosynovitis, peritendinitis and the tennis elbow syndrome. Scand J Work Environ Health 1984;10:443-9.

5. Roto P, Kivi P. Prevalence of epicondylitis and tenosynovitis among meatcutters. Scand $\mathbf{J}$ Work Environ Health 1984;10:203-5.

6. Dimberg L. The prevalence and causation of tennis elbow (lateral humeral epicondylitis) in a population of workers in an engineering industry. Ergonomics 1987; 30:573-80.

7. Luopajärvi T, Kuorinka I, Virolainen M, Holmberg M. Prevalence of tenosynovitis and other injuries of the upper extremities in repetitive work. Scand J Work Environ Health 1979;5(suppl 3):48-55.

8. Viikari-Juntura E. Neck and upper limb disorders among slaughterhouse workers: an epidemiologic and clinical study. Scand J Work Environ Health 1983;9:283-90.

9. Mausner JS, Bahn AK. Measures of morbidity and mortality. In: Mausner JS, Bahn AK, ed. Epidemiology: an introductory text. Philadelphia, London, Toronto: WB Saunders Company, 1974:126-59.

10. Kurppa K, Viikari-Juntura E, Kuosma E, Huuskonen M, Kivi P. Incidence of tenosynovitis or peritendinitis and epicondylitis in a meat-processing factory. Scand J Work Environ Health 1991;17:32-37. 
11. Silverstein BA, Fine LJ, Armstrong TJ. Hand wrist cumulative trauma disorders in industry. $\mathrm{Br} \mathrm{J}$ Ind Med 1986;43:779-84.

12. Kuorinka I, Jonsson B, Kilbom Å, Vinterberg $H$, Biering-Sörensen F, Andersson G, Jörgensen K. Standardised Nordic questionnaires for the analysis of musculoskeletal symptoms. Appl Ergon 1987;18:233-7.

13. Miettinen OS. Simple interval estimation of risk ratio. Am J Epidemiol 1974;100:515-6.

14. Miettinen OS. Estimability and estimation in casereferent studies. Am J Epidemiol 1976;103:226-35.

15. Armitage P. Test for linear trends in proportions and frequencies. Biometrics 1955;11:375-86.

16. Allander E. Prevalence, incidence and remission rates of some common rheumatic diseases or syndromes. Scand J Rheumatol 1974;3:145-53.

17. Kuorinka I, Koskinen P: Occupational rheumatic diseases and upper limb strain in manual jobs in a light mechanical industry. Scand $\mathbf{J}$ Work Environ Health 1979;5(suppl 3):39-47.

18. Fischer AA. Pressure algometry over normal muscles: standard values, validity and reproducibility of pressure threshold. Pain 1987;30:115-26.

Received for publication: 4 May 1990 